\title{
FRACTURE-TOUGHNESS TESTS ON A HIGH-STRENGTH BERYLLIUM FROM ROOM TEMPERATURE TO $300^{\circ} \mathrm{C}$
}

Mark Per ia

Iain Finnie

March 10, 1975

Prepared for U.S. Energy Research \& Development

Administration under contract No. W-7405-Eng-48

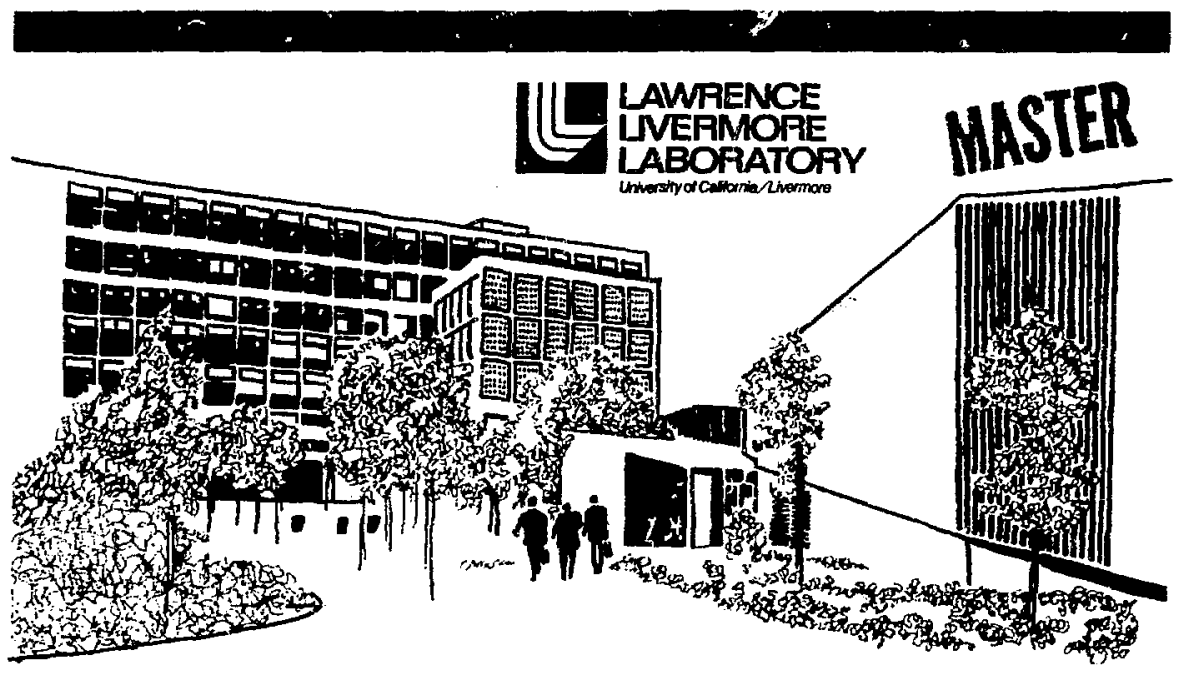




\section{Notice}

"Thls report was prepared as an account of work sponsored by the United States Government. Neither the Unjted States nor the United States Energy Researsh \& Development Administration, nor any of their employers, hat any of their contsactors, subcontractors, of theit employees, makes my warranty, express or implied, $r e$ ussumes any legal wintinty or responsibility for the eccuracy. completeness or usefulness of any Information, apparatus, product or process disclosed or represents that its use would not infringe privately-owned rights."

Printed in the United States of America Available from

National Technical Information Service

U. S. Department of Commerce 5285 Port Royal Road Springfield, Virginia 22151

Price: Printed Copy $\$$ _ Microfiche $\$ 2.25$

\begin{tabular}{c} 
* Pages \\
\hline $1-50$ \\
$51-150$ \\
$151-325$ \\
$326-500$ \\
$501-1000$
\end{tabular}

NTIS

Selling Price

$\$ 4.00$

$\$ 5.45$

$\$ 7.60$

$\$ 10.60$

$\$ 13.60$ 


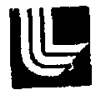

LAMRENCE LNEAMORE LABORATORY

chmosityd Calomig Liemore.Caliamia. 94550

LCRL-51774

\section{FRACTURE-TOUGHNESS TESTS ON A HIGH-STRENGTH BERYLLIUM FROM ROOM TEMPERATURE TO $300^{\circ} \mathrm{C}$}

Mark Perra

Iain Finnie

MS. Date: March 4, 1975

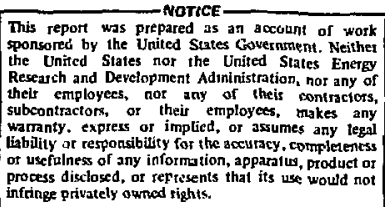

disclosed, or represents that its ute would or

process disclosed, or fertesents that its we wowd not
infinge privately owned tights. 


\section{Foreword}

Mark Perra performed the experiments described in this report while employed by LI.L in the summer of 1973 . He is presently a graduate student in the Departnent of Nechanical Engineering at the tniversity of California at Berkeley. Iain Finnie is a consultant to LLL. He is a Professor of Mechanical Engineering at the Lniversity of California at Borkeley. 


\section{Contents}

\begin{tabular}{|c|c|c|c|c|c|c|c|c|c|c|c|c|c|c|c|c|}
\hline Abstract & $\cdot$ & . & • & . & . & - & $\cdot$ & - & - & . & . & - & - & - & - & 1 \\
\hline Introduction & . & - & . & . & • & - & . & . & - & $\cdot$ & . & - & - & • & - & \\
\hline Materials and & Net & hods & & • & • & - & - & - & - & • & . & • & - & - & - & \\
\hline Specimens & & - & - & - & . & - & . & . & - & . & • & . & . & . & . & \\
\hline Fatigue Pre & ecra & cokıng & & $\cdot$ & . & - & . & - & • & . & - & • & . & - & . & \\
\hline Fracture-T & ough & ness & Tes & sting & & - & . & - & - & . & - & . & - & - & . & \\
\hline Crack-1eng & th $D$ & eter & $\min a$ & ation & & - & . & - & . & . & . & - & . & . & - & \\
\hline Fractograpl & & . & . & - & . & . & - & • & . & . & • & . & - & - & . & 6 \\
\hline Results and Di & iscus & ssion & & - & - & . & - & * & • & - & - & - & . & - & - & 6 \\
\hline Fatigue Pre & ecra & cking & & $\cdot$ & - & . & . & . & • & • & - & - & . & - & . & 6 \\
\hline Load Displa & acem & eent & Reco & rds & & - & . & - & . & • & - & - & - & - & . & t \\
\hline Crack-Leng & sth $D$ & Beter & $\min$ & ation & & . & . & - & - & - & - & • & - & - & . & 10 \\
\hline Numerical & Valu & les of & $\mathrm{Fr}$ & acture & & ough & gess & • & . & • & . & . & - & - & - & 12 \\
\hline Fractograph & & - & - & - & - & $\cdot$ & - & . & - & • & - & • & - & • & - & 16 \\
\hline Conclusions & - & . & - & - & - & $\cdot$ & - & - & - & . & - & - & - & - & • & 18 \\
\hline Acknowledgme & nts & & $\cdot$ & • & - & . & $\cdot$ & - & - & • & • & - & - & - & • & 19 \\
\hline References & • & - & . & - & • & $\cdot$ & - & - & - & . & . & - & . & . & - & 19 \\
\hline Appendix A & - & - & . & - & • & $\cdot$ & - & - & - & . & • & - & - & - & - & 20 \\
\hline Compliance & Cal & ibrat & ion & & - & - & - & . & - & . & . & • & - & - & $\cdot$ & 20 \\
\hline Appendix B & $\cdot$ & $\cdot$ & - & - & • & • & • & $\cdot$ & $\cdot$ & . & . & - & . & - & • & 21 \\
\hline Calculation & & $\max$ & & - & $\cdot$ & $\cdot$ & $\cdot$ & • & * & - & - & - & - & - & - & 21 \\
\hline
\end{tabular}




\title{
FRACTURE-'TOUGHNESS TESTS ON A HIGH-STRENGTH BERYLLIUM FROM ROOM TEMPERATURE TO $300^{\circ} \mathrm{C}$
}

\begin{abstract}
As one step in the characterization of its mechanical, metallurgical, and physical properties, the temperature dependence of the fracture toughness of a high-yieldstrength grade of hot-pressed beryllium block was determined over the range between room temperiture and $300^{\circ} \mathrm{C}$. Fatigue cracks were generated in 8.92 $\mathrm{mm}$-thick double-cantilever beam specimens by a reversed-loading method. Room-temperature fracture-toughness data from tests on specimens with Eloxmachined notches and fatigue precracks were compared. Electron fractographs of fatigue and fast-fracture regions

were obtained. l.oad-displacement records generated frim tests on specimens with natural cracks were nonlinear, whereas tests on specimens with machined cracks gave the expected linear records. Evidence points to a crack-closure phenumenon rather than plasticity as the source of the nonlinearity. The fracture-toughness data indicate that for this material the mean vaiue of the toughness increases from $9.0 \mathrm{MPa} \cdot \mathrm{m}^{1 / 2}\left(8.1 \mathrm{ksi} \cdot \mathrm{in}^{1 / 2}\right)$ to 10. $8 \mathrm{MPa}^{\mathrm{m}} \mathrm{m}^{1 / 2}\left(9.7 \mathrm{ksi} \cdot \mathrm{in}^{1 / 2}\right)$ between $23^{\circ} \mathrm{C}$ and $300^{\circ} \mathrm{C}$. These values are among the lowest ever reprirted iur beryllium.
\end{abstract}

\section{Introduction}

Beryllium is an attractive maturial for applicatior.s in which moderately high yield strength, high elastic modulus, low density, and good fatigue resistance are desirable. The principal feature of beryllium which interferes with full realization of its potential as a structural material in specialized applications is its tendency to brittle fracture at low stress in:ensities. At room temperatures, tensile elongations of less than $3 \%$ are commonly

\footnotetext{
"Reference to a company or product name does not imply approval or recommendation of the product by the University of California or the Energy Research \& Development Administration to the exclusion of others that may be suitable.
}

reported for hot-pressed berylium; no shear lips are evident on fracture sur faces and cleavage mechanisms lominate. The propensity of beryllium to brittic fracture presumably arises from its ease of cleavage on sereral planes tmost conspicuously the basal plane) and the resistance of its lattice to the generation and motiou of dislocations having a component resolvable along the c-axis.

The influence of elevated temperatures on the resistance of beryllium to fracture is largely undetermined, although this is a problem of considerable practical significance. Such information would be of value, for instance, in a program for 
controlling the fracture of welded parts. Welded beryllium parts frequently fail as a result of the propagation of cracks in tensile fields which are present in the vicinity of the welds. In at least some cases, preheating can diminish cracking in welded beryllium parts.

The amount of data available in the literature on the elevated-temperature fracture toughness of bervllium is small. The results of Harrod et al. ${ }^{1}$ for $\mathrm{S}-200$ gracie beryllium indicate that between $23^{\circ} \mathrm{C}$ and $260^{\circ} \mathrm{C}$ the fracture toughness increases from about $20 \mathrm{MPa} \cdot \mathrm{m}^{1 / 2}$ $\left(18 \mathrm{ksi} \cdot \mathrm{in}^{1 / 2}\right)$ to $38 \mathrm{MPa} \cdot \mathrm{m}^{1 / 2}\left(34 \mathrm{ksi} \cdot \mathrm{in}^{1 / 2}\right)$. The value for $250^{\circ} \mathrm{C}$ was based on the results of a single test. More recently, the data of Shabbits and Logsdon ${ }^{2}$ on S-200 grade beryllium indicated no appreciable increase in toughness between $23^{\circ} \mathrm{C}$ and $150^{\circ} \mathrm{C}$ but showed a rapid increase in toughness between $150^{\circ} \mathrm{C}$ and $260^{\circ} \mathrm{C}$ gosing: from about 10 N1Pa. $\mathrm{m}^{1} 2$ (9 $\left.\mathrm{ksi} \cdot \mathrm{in}^{1}{ }^{2}\right)$ to about $16 \mathrm{MPPa} \cdot \mathrm{m}^{\mathrm{i}}$ '2 $\left(1+\mathrm{ksi} \cdot \mathrm{in}^{\mathrm{l}}\right.$ ?) respectively. These values were cibtained from fat igue-precracked compact-tensior specimens orientcd with the crick plane perpendicular to the pressing direction, and were based on the results of three tests at $150^{\circ} \mathrm{C}$. and two tests at $260^{\circ} \mathrm{C}$. In this temperature range, no data were generated from specimens oriented with the crack plane parallel to the pressing direction.

The present study has been undertaken with the objective of det rmining the temperature dependence of the fracture toughness of a high-yield-strength grade of beryllium between room tempe rature and $300^{\circ} \mathrm{C}$; and is part of a broader program of characterizing the mechanical, metallurgical, and physical properties of this material.

\section{Materials \&nd Methods}

\section{SPECTMENS}

The beryllium used in this study was a vacuum-hot-pressed block of high-yield material supr?ied by Brush-Wellman. The chemistry was within the limits of S-200 grade, but a deliberate attempt was made to produce a high yield-strength. Selected chemical, physical, and mechanical properties of this material are listed in Table 1. The physical and tensile properties are those obtained by Gelles. 3 The chemical analyses listed in Table 1 are those forablished by Brush-Wellman and by the Battelle Columbus Laboratory. In comparison with most commercial grades of beryllium, this material has a rather low density, a small grain size, and a high iron content. Based on iron content, as determined by wet chemical methods at Battelle, and on aluminum content, as determined by neutronactivation analysis, the iron/aluminum ratio is 3.2 .

The specimens were cut from the highyield block in two crack-plane orientations with respect to the pressing direction. There were 15 transverse specimens (i.e., irack-plane parallel to the pressing direction). These were numbered GL1 to $G$ T 15. In addition, there were 10 longitudinal specimens (i. e., crack-plane perpendicular to the pressing direction). These specimens were numbered DE1T to DC010T.

The double-cantilever beam (DCB) specimens, which were $8.91 \mathrm{~mm}$ thick, 
'ruble 1. Selected chemical, mochanical, and physical propertics of high-yield-grade berilium.

\begin{tabular}{|c|c|c|c|}
\hline & \multicolumn{3}{|c|}{ Chemical Composition } \\
\hline & \multirow[t]{2}{*}{ Prush-Mellmass } & \multicolumn{2}{|c|}{ Battelle Columbus Laboratory } \\
\hline & & $\begin{array}{c}\text { Chemical } \\
\text { Determination } \\
\text { (ppm) }\end{array}$ & $\begin{array}{l}\text { Determination by } \\
\text { neutron-ct:ration } \\
\text { analysis (ppm) }\end{array}$ \\
\hline ReO & $20,0 \pm 0$ & - & 14,100 \\
\hline $\mathrm{Fe}$ & 1,680 & 1,500 & - \\
\hline C & 1,230 & $1,+30$ & - \\
\hline Al & 620 & 400 & 469 \\
\hline $\mathrm{Mg}$ & 80 & 60 & - \\
\hline $\mathrm{Si}$ & $47 n$ & 200 & - \\
\hline
\end{tabular}

Tensile Properties (B. $5 \times 10^{-3} \mathrm{~mm} / \mathrm{sec}$ al room temperature)

Property

Value

$0.2 \%$ offset yield strength $(\mathrm{MPa}$ )

338

Uitimate strength ( $\mathrm{MPa}$ )

386

Total elongation (\%)

2. 1

Reduction of area $(\%)$

2.6

Density (\%is of theoretical)

99.45 to 99.71

Grain size $(\mu \mathrm{m})$

$8.8 \pm 0.03$

were pin loaded in tension. Figure 1 is a diagram of such a specimen. Changes of the dimension $\delta$ were recorded during tests. An Elox slot, shown enlarged below the figure, was $0.102 \mathrm{~mm}$ wide and $1.27 \mathrm{~mm}$ long. The distance between the line consecting the centers of the loading pin holes and the tip of the Filox slot was $10.4 \mathrm{~mm}$. Two side-grooves functioned to maintain directional stability of the crack. The depth of the Elox side-grooves ras $0.610 \mathrm{~mm}$ and the diameter at the root of the groove Was $0.102 \mathrm{~mm}$.

\section{FATIGLE PRECRACKING}

Some specimens were tested with the notch in the as-Eloxed condition but, most frequently, fatigue cracks were grown beyond the tip of the notch. In view of the amount of success in the controlled growth of fatigue cracks using reversed loading, which has been reported by Jones $\mathrm{e}_{\mathrm{i}}$ al. and by others, 2,5 this technique was used in the present work. Fatigue cracks were produced by reversed loading, with the ratio of maximum-to-minimum applied load equal to -1 . The controlled-displacement mode of a hydraulic materialstesting system was used, at a frequency of load reversal of $20 \mathrm{~Hz}$. A minimization of unwanted displacements in the rigid load train was accomplished by using tight-fitting loading pins and pretorqued connections. Because no universal joints were used, care was taken in alignmen: 


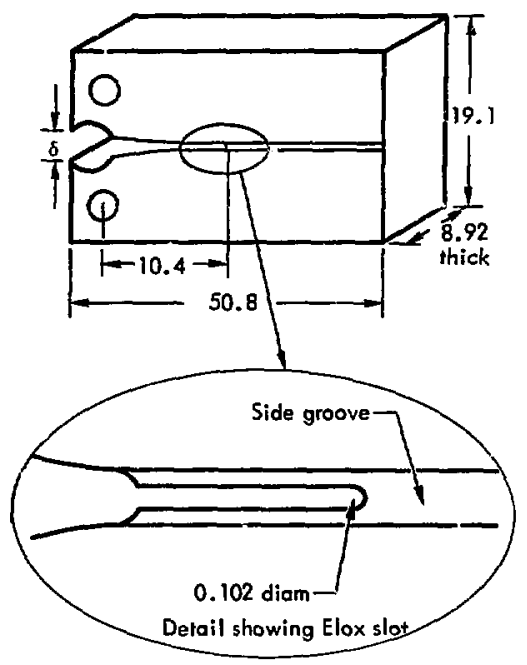

Fig. 1. A doible cantilever beam (DCB) specimen. Dimensions are ir. $\mathrm{mm}$.

to minimize eccentric loading on the specimens. The alignment of the loading grips allowed the loading pins a deviation from parallel of no more than 0.08 degree.

The specimens were fatigued in reversed loading for anywhere from $5 \times 10^{4}$ to $8 \times 10^{4}$ cycles at a preselected displacement. The prosedure was repeated with progressively increasing displacernents until a fatigue crack was initiated. These cracks were grown to about $1.27 \mathrm{~mm}$ in length. Maximum fatigue loads varied up to $844 \mathrm{~N}$, which corresponded to a fatigue stress intensity $\mathrm{K}_{\mathrm{f}}$ of approximately 6. $5 \mathrm{MPa}^{\mathrm{M}} \mathrm{m}^{1 / 2}\left(5.9 \mathrm{ksi}^{\mathrm{inh}} \mathrm{in}^{\mathrm{i} / 2}\right.$.

\section{FRACTLRE TOLGHNESS TESTING}

Specimens were pulled to fracture in an $89 \mathrm{kN}$ Instron machine at a crosshead speed of $2.12 \times 10^{-3} \mathrm{~mm} / \mathrm{sec}$. The tensile load was measured with a $4.45 \mathrm{kN} \mathrm{l}$ rad cell. A clip gage measured the relative displacement of the knife edges at the loading end of the sperimen. That is, the gage measured changrs in the dimension of $b$ in Fig. 1.

Specimens for the high temperature tests were heated in an argon atmosphere with a conventional instron furrice. Temperature measuremeri was made by a plainum/platistin-rhodiuts thermocouple in contact with tire specimen. The change of specir en temperature during a test never exceeded $2^{\circ} \mathrm{C}$. The clip gage used for" measu ing displacement was marte of a type 416 ferritic stainless steel. A strain-gage adhesive which would remain stable at temperatures up to $310^{\circ} \mathrm{C}$ as selected. The clip gage was calibrated at high temperatures $(15)^{\circ} \mathrm{C}$ and $300^{\circ} \mathrm{C}$ by means of the specially designed apparatus shown in Fig. 2. A quartz rod and a concentricaily fitted quartz tube were extended from the exterior to the interior or the Instron furnace through an access port. Outside the furnace, the tude was attached to the body of a rai sel micrometer while the quartz rod was affixed to the spindle of the micrometer. In the interior of the furnace the two clip gage arms were seated on mating knife edges $a^{++}$ach $d$ to the tube and rod respectively. Thus, rotation of the barrel micrometer resulted in a relative displanem, at of the rod and tube and thereby allowed calibration of the clip gage.

Specimen compliance was calibrated by the same procedure as that used for performing fracture-toughness tests except that the Eloy slut "'ms ex =nded by machining. The $0.102 \mathrm{~mm}$-wide slot 
(Fig. 1) was increased in length in $1.27 \mathrm{~mm}$ increments and the corresponding relation brtween applied load and opening displacement was then recurded. Because opening displacements were neasured at the end of the specimen rather than nder the point of loading, a correction factor was applied to the apparent compliance to determine the actua' sperimen compliance. The correction, derived by Finnie and

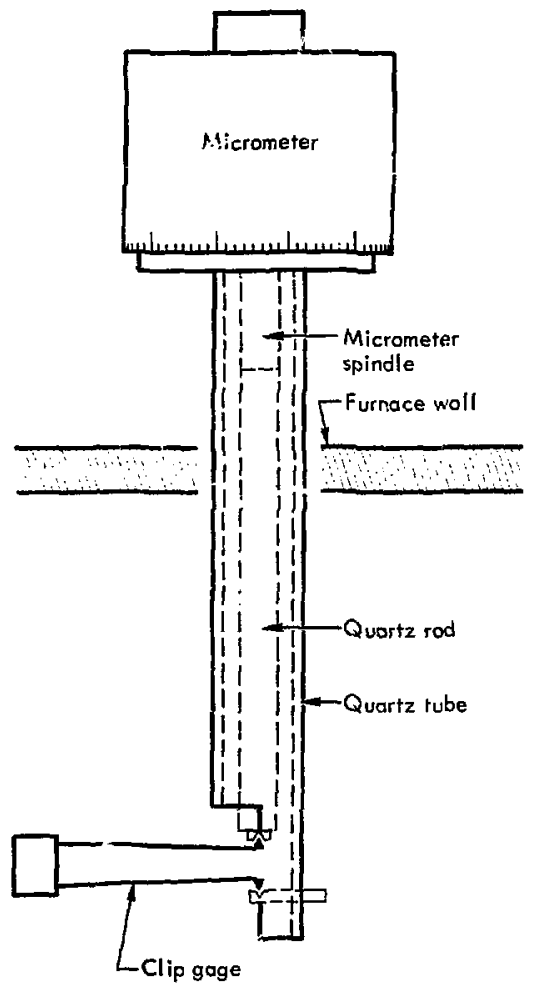

Fig. 2. Elevated-temperature clip gage calibration apparatus, published in Prado, ${ }^{\mathfrak{b}}$ is

Cactual

$$
=C_{\text {apparent }}-\frac{5 \gamma}{\mathrm{Ebh}}\left[(1+\cdots)+2\left(\frac{\mathrm{a}+0.6 \mathrm{~h}}{\mathrm{~h}}\right)^{2}\right]
$$

where $\gamma$ is the perpendicular distance from the center of the loading pins to the knife edges at the end of the specimen, $F$ is Young's modulus, $v$ is Poisson's ratio, and $b$ and $h$ are the cantilever thickness and height respectively.

After establishing the compliance of the specimen as a function of crack ler.:the energy-release rate $G$ is then computed using $d C / d \%$, through the standard relation

$$
G=\frac{P^{2}}{2 b_{X}}\left(\frac{d C}{d a}\right)
$$

where $P$ is the applied ioad and $b_{N}$ is the specimen thickness between the side-groove roots. The opening-mode stress intensity fra plane strain is determined from $G$ by

$$
\mathrm{K}_{\mathrm{I}}=\left[\frac{\mathrm{GE}}{1-v^{2}}\right]^{1 / 2}
$$

Because maximum fracture loads were used to compute the critical stress intensity factors, the toughiness data are designated by $K_{\max }$ rather than by $K_{\mathrm{IC}}$.

\section{CRACK LFNGTH DITERMINATION}

After fatigue precracking or iracturetoughness testing, crack-length masurements were generally made on both sides of the specimen, using an opticai micruscope at $100 \mathrm{X}$ magnification. As will be discusseo below, lapping the side gruoves before testing allowed impror d resuiution of cracks. The lapping was periormad 
with $0.305 \mathrm{~mm}$-thick brass shimstock and 600 - and 900 -grit alumina abrasive. The lapping deeprned the side grooves by about $0.051 \mathrm{~mm}$ anc' somewhat sharpened the root. Because optical techniques of racklength determination frequently gave results lacking consistency and reproducibility, other techniques were utilized, inclucing ultrasonic, radiographic, and dye-penetrani methods. In addition, crack length dettrminations weje made with a scanning electron microscope. buring festing, erick longths were also obtained indirectly uy comparing the experinientally-cietermined specimen compliance with the standard plot of compliance vs crack length.

\section{FRACTOGRAPHY}

Scanning electron fractographs were made of fatigue surfaces and of lowand high-temperature fast-fracture surfaces.

\section{Results and Discussion}

\section{FATIGLE PRECRACKING}

By applying fatigue stress intensities of $6.5 \mathrm{MPa} \cdot \mathrm{m}^{1 / 2}\left(5.9 \mathrm{ksi} \cdot \mathrm{in}^{1 / 2}\right)$ using reversed loading with the maximum compressive load equal to the maximum tensile load, fatigue cracks were generally observed to initiate and grow to approximately $1.27 \mathrm{~mm}$ in length in $8 \times 10^{4}$ ¿vcles. At slightly smaller fatigue stress intensities, for example $5.6 \mathrm{MPa} \cdot \mathrm{m}^{1 / 2}$ ( $5 \mathrm{ksi}^{-} \mathrm{in}^{1 / \mathrm{k}}$ ), no crack was observable after a similar number of cycles. It is very likaly that this value for $\mathrm{K}_{\mathrm{f}}$ does not satisfy the ASTN requirement of $\mathrm{K}_{\mathrm{f}}<0.6 \mathrm{~K}_{\mathrm{IC}}$ for this material. Difficulty was encountered in propagating fatigue cracks in a controlled manner at the stress intensities employed, and erratic growth rates were frequently observed.

It should be pointed out that when compressive loads are applied to specimens, the stress field near the crack tip is not necessarily compressive. A tensilestress field can be generated in the vicinity of $a$ compressiveij loaded material discontinuity as a result of the applied load. Whether the stress is tensile or compressive may depend strongly on the length of the crack and on the geometry of the body. To illustrate this point, we can model the DCB specimen under applied compressive loads as an elastic beam on a rigid foundation (lower portion of Fig. 3 ). By the symmetry of the specimen and of the applied loads, the clisplacement in the $Y$ direction at $x=a_{i}$ must vanish. The siriple support at $\mathbf{x}=a_{i}$ enforces this condition in the model. By examining the model at $x=a_{i}+B$ one can infer that an opening force is present at the tip of the crack in the cracked specimen due to the applied compressive load. If we had chosen as a model an elastic beam on an elastic foundation, this result would remain the same. Consequently, caution must be observed in applying large compressive loads to these specimens when employing reversed-loading techniques. The nature of the stress field at the crack tip is unknown and the extent of the damage at the crack tip from potentially large 
whsile stress mtensities is underepmined. This diflielly does nol arise in trecersed Juading of bend specimens providing the fatigure crack does not cross the neut ral axis of stress.

\section{LOAU-DISPLACFMENT RIECORDS}

Figure 4 is a plot of the observad compliance (correcteo for the location of displacement measurement) versus machined crack length. Also plotted is the analytic expression determined by Mostovoy ${ }^{7}$, i. e.

$$
C=\frac{8}{\mathrm{Ebh}^{3}}\left[(\mathrm{a}+0.6 \mathrm{~h})^{3}+\frac{3(1+v) \mathrm{ah}^{2}}{4}\right] .
$$

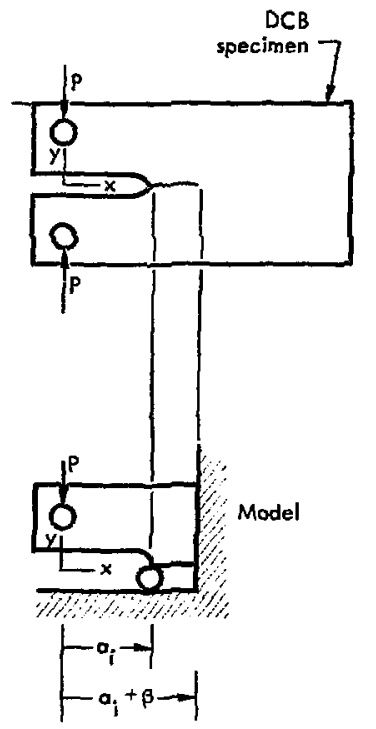

Fig. 3. DCB specimen under a compressive load modeled as an elastic beam on a rigid foundation.

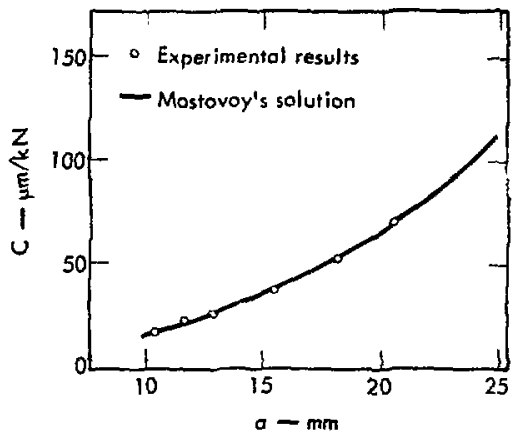

Fig. 4. Experimentally cietermined compliance calibration corrected for the location of risplacement measuren'،nt.

The data for these plots are tabulated in Appendix A. It can be seen from Fig. 4 that the experimental and the analytical results agree very well. The compliance calibration at $300^{\circ} \mathrm{C}$ also agrees well with these results, undicating that between $23^{\circ} \mathrm{C}$ and $300^{\circ} \mathrm{C}$ compliance is not a function of temperature. The load-displacement records for these compliance tests were jinear from small loads up to loads which were comparable to those used for crack propagation in a fracture-toughness test. Within the sensitivity of the clip gage, displacements were completely reversible after unloading the specimen.

For specimens with natural cracks, however, the load-displacement-record linearity depended strongly on the length of the crack. For cracks which extended only short distances $(\leqslant 1.5 \mathrm{~mm}$ ) beyond the tip of the Flox slot, the record was essentially linear up to the point of fracture, and satisfied ASTM linearity requirements, Nonlinearity became more pronounced for longer cracks. An example 


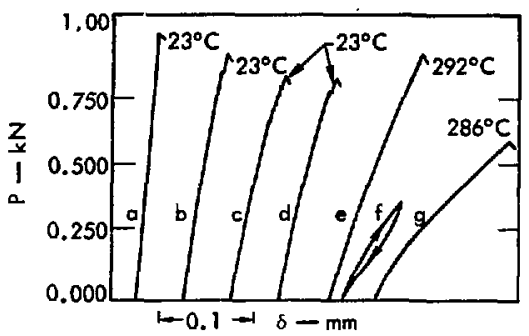

Fig. 5. Load displacement record for specimen GL-4.

of this behavior is given in Fig. 5 which is the load-displacement record for specimen GL-4. For long crack-lengths, the curvature of the record decreases with increasing loads; linearity is most closely approximated at higher loads.

As shown in Fig. 5, curve $f$, if a subcritical load (that is, a load which was less than that required to extend the crack) was applied to a specimen with a long natural crack, and if the specimen was subsequently unloaded, the unloading curve did not coincide with the loading curve. This curve also indicates no appreciable residual displacement after a complete loading-unloading cycle.

Because the nonlinearity shown in Fig. 5 persisted over substantial fractions of the load deflection records, and because nonlinearity was never observed with machined cracks tested under identical conditions, it cannot reasonably be attributed to errors in the measurements of loads or displacements. Faulty seating of the clip gage or the loading pins must be ruled out as possible sources for this effect. Further, because the nonlinearity decreased with increasing loads and because there were no observable residual displacements on unloading from subcritical loads, crack-tip plasticity and plastic flow in the vicinity of the loading pins must also be ruled out.

The nonlinearity manilested itself as increasing specimen compliance with increasing load. This phenomenon has been observed by lones, Bubsey, and Brown ${ }^{4}$ in beryllium bend-specimens and has been discussed in Appendix $\mathrm{C}$ of their paper. These authors suggested thit the nonlinearity was associated with the crackclosure phenomenon described by Elber. ${ }^{8}$ Elber has defined a crack as being closed when the compliance of the body is the same as the compliance of an identical but uncracked body under the same load system. Assume for the moment that a crack of length $a$ in an unloaded elastic body is closed due to internal torces which exist in the body. Then, as loads are applied which overcome the closing forces and gradually open the crack, the compliance will also gradually increase from that of an uncracked body to that of a body with an open crack of length a.

If we postulate the existence of crackclosing forces, we can explain the dependence of compliance on applied load as exhibited by these specimens. The crack may be considered to consist of both open and closed part $s$; that is, as shown in

Fig. 6, part a,

$$
a=a_{0}+a_{c} \text {. }
$$

As a result of the postulated closing forces, $a_{0}$ increases monotonically with $P$ and the compliance smoothly increases with $P$, as shown in Fig. 6, part $b$. It is apparent that the nonlinearity would be especially prominent for DCB specimens $w$ ith long cracks (a being several times larger than $a_{\mathbf{i}}$ ). 
The influence of cruck 1.$]$ isure on esmplianes in the DC'3 specimen was demonstrated by the follow ing lecthnique: A $0,102 \mathrm{~mm}$-wide 1:lox slot was machined in a specimen to simulate a long $1 \mathrm{a}=30 \mathrm{~mm}$ ), open crack. A tensile load $267 \mathrm{~N}$ was applied to the sperimen. This would correspond to a stress intensity of 4. $4 \mathrm{MPa} \cdot \mathrm{m}^{1 / 2}\left(4 \mathrm{ksi} \cdot \mathrm{in}^{1 / 2}\right)$ if it were applied to a specimen $w i t h$ a natural crack

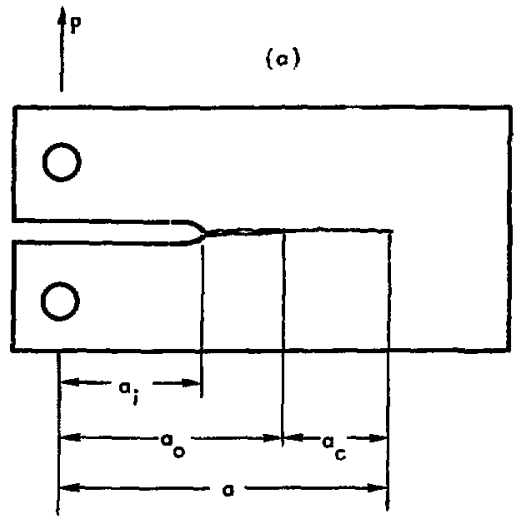

(b)

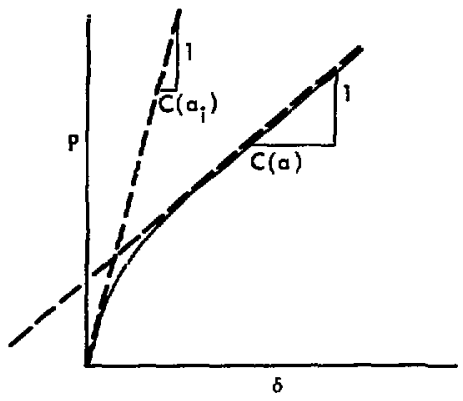

Fig. 6. The influence of gradual crack opening on the compliance of the DCB specimen. of the sam* length. The load-displacement recurd was linear. Shimstock slightly thicker than the slot was then placed between thu separated arms of the specimen, with the steck wedged as close to the notch tip as int erference would allow. Subsequent loa:-displacement records showed stroner nonlinearities similar to that of Fig. 6, par $i b$.

Measurements of opening displacements neas the ip of a long (about $20 \mathrm{~mm}$ ), natural crack were made as a function of applied load. The reference points for displacement measurement were attached rigidly to both arms of the DCB specimen at a small distance (about $2.5 \mathrm{~mm}$ ) behind the crack tip. The signal from the nighsensitjuity displacement transducer was displayed directly on a digital voltmeter. The resulting plot of load vs displacement, Fig. 7, indicates that substantial loads

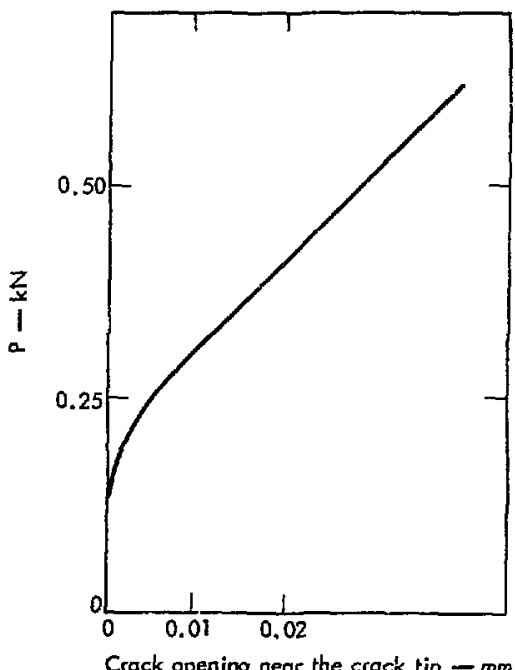

Fig. 7. Load vs crack opening near the tip of a long natural crack. 
(about $220 \mathrm{~N}$ ) had to be applied before any resolvable displacement occurred.

Further increases in load caused appreciable displacements. These data are consistent with the hypothesis that a crack-closing phenomenon did play a role in the observed nonlinearities.

The problem of the origin of the postulated crack-closing forces in a naturally cracked specimen remains to be explained. It is likely that the crack faces do not fit perfectly on unloading because of plastic deformation left in the wake of the crack. For beryllium, the amount of deformation must be small, but it may be sufficient to cause this effect. As the applied load was removed, the putative lack of fit would prevent the arms of the specimen from returning to their original position with respect to one another. Consequently, a residual compressiveforce would be transmitted across the points of contact of the crack faces. In this manner, crack-face interference could generate internal forces leading to nonlinearities of the load-displacement record.

In these experiments, microcracking frequently occurred and revealed itself as small steps in the load-displacement record. (See, for example, Fig. 5, curve c). These events were detected by an acoustic transducer. No optically observable increase in crack length was produced by microcracking. As pointed out by Jones et al. , ${ }^{4}$ microcracking is to be expected in berylliun in the light of its very low basal-plane fracture propagation energy.

\section{CRACK-LENGTH DETERMINATION}

None of the several methods used in the determination of crack length in the
DCB specimen proved to be completely satisfactory. Initially, an indeavor was made to establish crack length on the basis of observations with an optical microscope. This method had several drawbacks. For example, in the asEloxed condition the surface of the root of the side groove proved to be unsatisfactory for crack observation due to its high reflectivity and unevenness, as shown in the top part of Fig. 8. Lapping the groove improved this condition, as shown in the bottom portion of Fig. 8, but accurate measurement remained difficult. Because the depth of focus was limited, only a narrow band of the side groove could be in focus at a time and cracks which wandered up the side of the grooves were difficult to locate and follow.

Lltrasonic methods of crack length determination were attempted. These methods occasionally indicated th the crack front was not straight. An example
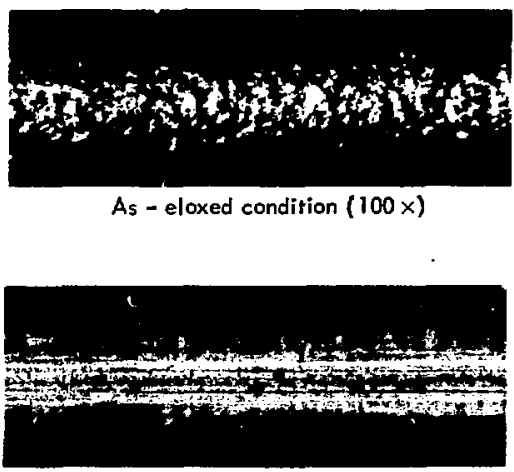

After lopping and fotigue precracking $(200 x)$

Fig. 8, Root of side groove before and after lapping and fatigue precracking. 


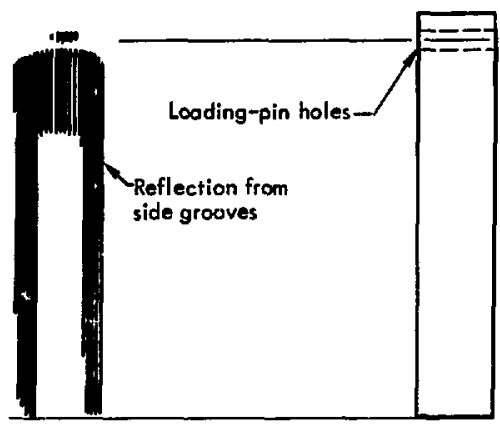

Fig. 9. Scan of reflected ultrasonic signal from plane of the crack for specimen GL-1. Reflection from side grooves interferes with crack observation.

of this is shown in Fig. 9, which is a recurd of the intensity of the reflected signal from the plane of the crack for specimen GL-l. Note that the reflected signal from the side grooves interferes with crack detection. Ult rasunic techniques and $\mathrm{x}$-radiographic techniques both suffered from inadequate resolution in this application.

The scanning electron microscope was also used to check the measurements obtained by optical methods. Cracks were revealed which would not be visible in an optical microscope. One can infer from Fig. 10, which is a 10,000X electron micrograph of , crack in the root of a side groove, that optical measurements of crack length are likely to be biased towa.d short values. The large number of determinations required eliminated this as a routine method, however.

An indirect method of crack-length measurement involved comparing the experimentally determined compliance (drfined as the inverse of the slope of the linear portion of the load deflection record) with the standard plot of compliance vs crack length. For the cases in which the nonlinearity extended up to the critical load, the maximum compliance (corresponding to the minimum slope) was used. Of course, the assumption that maximum complic nce correctly reflects specimen compl:aice can be valid only if plasticity does not play a role in causing the nonlinearity. If crack closure was the dominant source of the nonlinearity, then the use of maximum compliance is valid. The correlation between the longest of the two optically determined crack lengths (obtained from the two sides of the specimen), and the crack length as determined from the observed compliance, was superior to the correlation between the average of the optical measurements

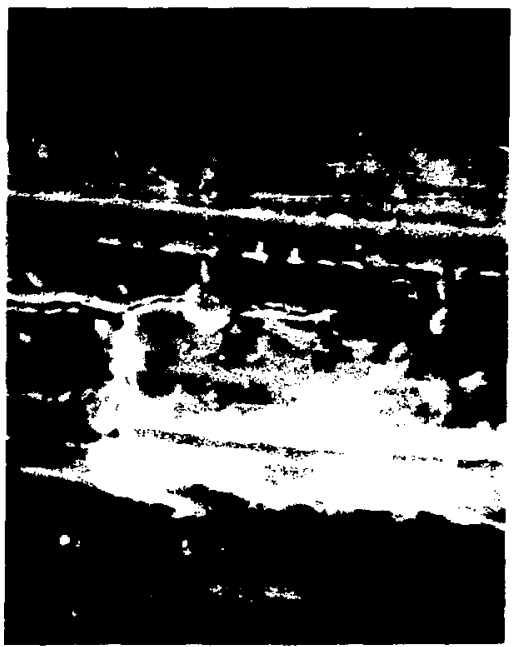

Fig. 10. Scanning electron micrograph of a fatigue crack in the root of a side groove $(10,000 \mathrm{X})$. 


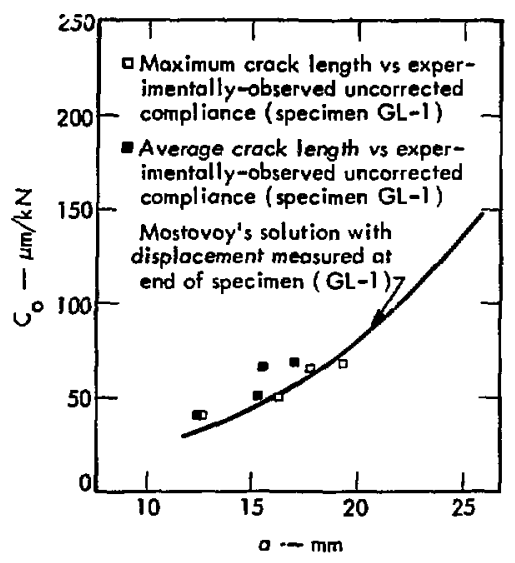

Fig. 11. Mostovuy's solution with displacement measured at end of specimen; maximum crack length vs experimentally observed uncorrected compliance; and average crack length $v$ s experimentally observed uncorrected compliance (Specimen GL-1).

and the compliance-crack length. This is demonstrated in Fig. 11 which plots (1) maximum crack length vs experimentally observed uncorrected compliance; (2) average crack length vs experimentally observed uncorrected compliance; and (3) Mostovoy's solution with dispiacement mer sured at the end of the specimen. As shown in Fig. 11, the superior correlation with maximum observed crack length was taken to be evidence that optically determined measurements were biased toward short values.

\section{NUMERICAL VALUES OF FRACTURE TOUGHNESS}

It was not possible to compute $\mathrm{K}_{\mathrm{IC}}$ values from the recorded data because of the nonlinearity of the load-displacement recrrds.
Maximunt $i$ ads wes ased th tompute the critical stress intensity factors. As mentioned previously, the maximum load did not always correspond to the initiation of rietectable cracking during a test. If acoustic-emission techniques had been employed in the determination of load for the calculation of fracture toughness, significantly smaller values of fracture toughness would have been derived. As discussed above, specimen compliance was used as an independent check on erack length. Occasionally, the discrepancy between the length of the crack as tetermined optically and ihe length as determined from specimen compliance exceeded $2.5 \mathrm{~mm}$. When this occurred, the uncertainty in crack length $(i$. e. the parameter a) was considered to be unacceptable and the data from that test were ruled to be inadmissible. The experimental data and the computations of $\mathrm{K}_{\max }$ are tabulated in Appendix $\mathrm{l}$. values of $\mathrm{K}_{\max }$ vs temperature for both transverse and longitudinal specimens are plutte in Figs. 12 and 13 respectively.

No significant differences are observed for $\mathrm{K}_{\max }$ between the transverse ard longitudinal oriertations. The fracturetoughness values may increase slightly with increasing temperature but the data are inconclusive in view of the scatter. The toughness values for room temperature tests range from 6.8 to 11.0 $\mathrm{MPa} \cdot \mathrm{m}^{1 / 2}\left(6.1\right.$ to $9.9 \mathrm{ksi} \cdot$ in $\left.^{1 / 2}\right)$. The average of 24 room temperature tests is $9.0 \mathrm{MPa} \cdot \mathrm{m}^{1 / 2}\left(8.1 \mathrm{ksi} \cdot \mathrm{in}^{1 / 2}\right)$. These values are among the lowest that have ever been reported for beryllium.

Figure 14 is a plot of $K_{\text {max }}$ vs crack length for the transverse specimens at $23^{\circ} \mathrm{C}$. An in'reasing trend in $\mathrm{K}_{\max }$ with 


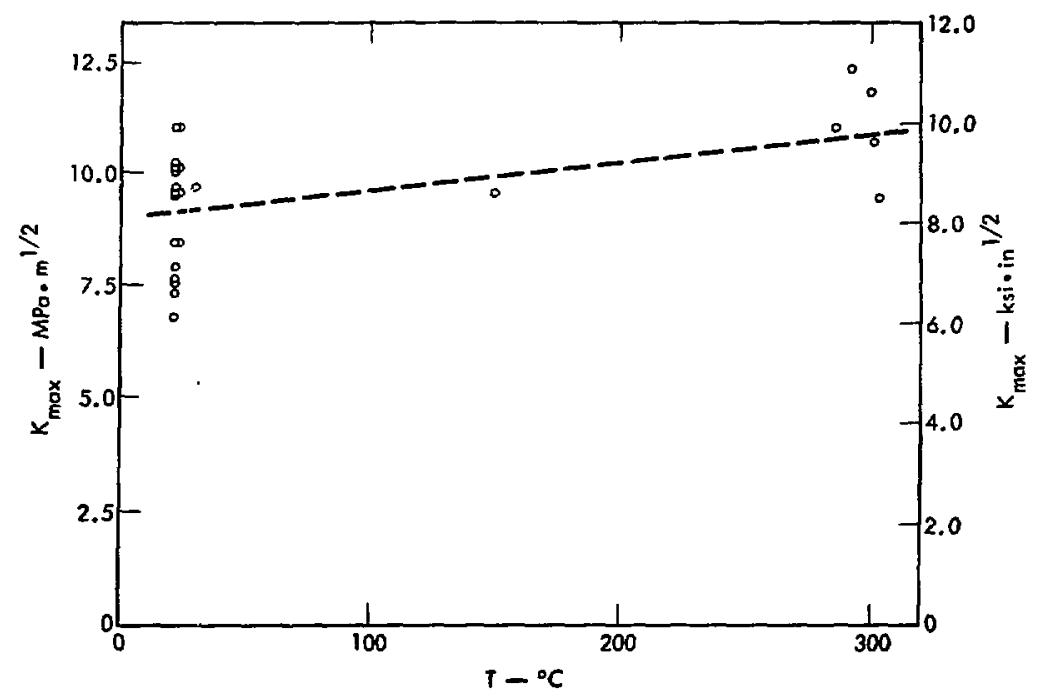

Fig. 12. $K_{\max }$ vs temperature for transverse specimens.

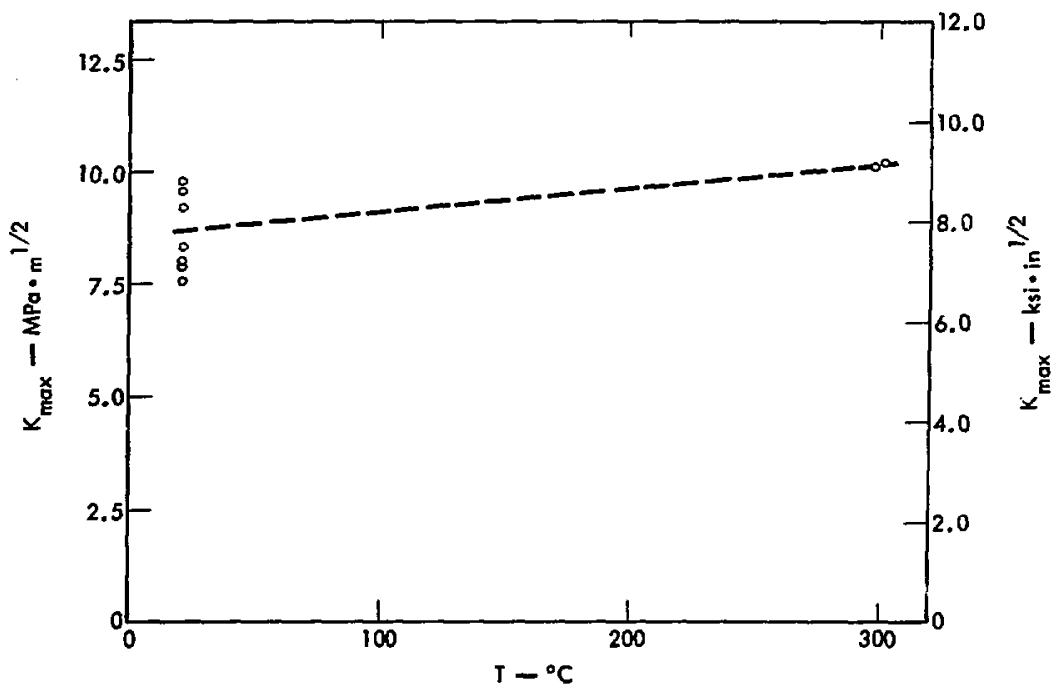

Fig. 13. $K_{\max }$ vs temperature for longitudinal specimens.

-13- 


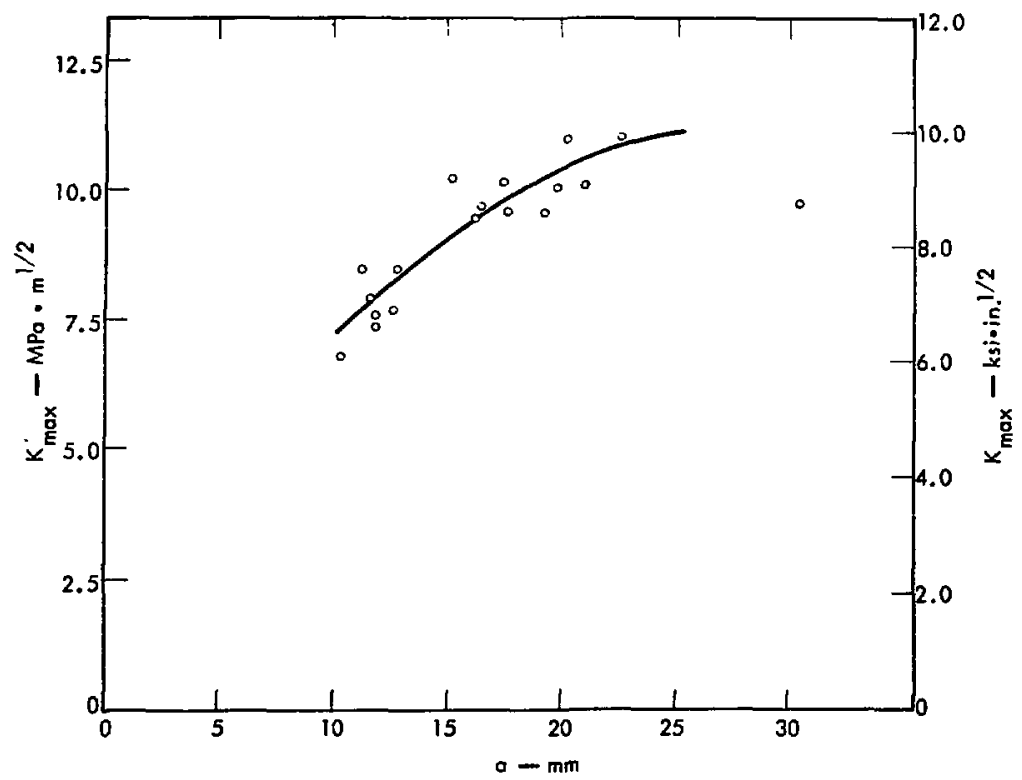

Fig. 14. $\mathrm{K}_{\max }$ vs crack length for transverse specimens at $23 \mathrm{C}$.

erack length is apparent for $10 \mathrm{~mm}$. a

$\therefore 15 \mathrm{~mm}$. A similar trend has been observed by Prado. "In that report, the $K_{\max }$ values derived for the first two or three data points generated from each DCB specimen were neglected. The inplied justification for omitting these points was the possible crack-tip damage induced by the wedge-loading technique which was used to initiate cracks. I'sing this technique, cracks were generated by impact wedging in a machined notch. The crack was arrested under an unspecified compressive load which was applied ahead of the notch. Because a trend of increasing $K_{\max }$ with crack length occurred in our studies when wedge loading was not used, alternate explana- tions must be considered. One explanation is that fliserepancies of this nature could be due to sustematic errors in the compliance calibration. That is, if the computed values for dC ida (which is proportional to $\mathrm{K}^{2}$ ) were systematically unclerestimated for $10 \mathrm{~mm}$ a $15 \mathrm{~mm}$, low $k$ values for this range of crack lengths would result. However, the close correspondence of the experimental compliance-calibration curve and Mostovoy's solution (Fig. 4) renders this explanation improbable.

Two other possible explanations would be the systematic overestimation of crack length for long cracks, and eccentric specimen loading. A fourth possibility is that the value of the stress intensity 
factor, k, is infunenced at flacture by the non-sinfulay lerms in the seriest sxpansion for stresses near the tip of a rerack. It has beren suggested by finnix and sain" that the second torm in the surites expansien has an influence on the diredional stability of cracks. Larsson and Carlsson 10 bave dimonstrated that for the same $k$ values, different types of specimons will have varying sizes of plastic zones in the casc of small-scale yielding at the crack iip. Rice ${ }^{11}$ has shown that in the series expansion the magnitude of the second term relative to the first, or singularitc term, is responsible for this effect. There is at this stage little clear-cut experimental evidence to show the influence of subsequent terms in the series expansion on fracture toughness. However, in the double-cantilever-beam test, the relative value of the second series-expansion term, relative to $K$. increases rapidly as crack length increases. The effect of this aspect of the specimen on fraciure toughness values needs further attention.

A simple experiment could test the proposition that crack tip damage causes the dependence of $\mathrm{K}_{\text {max }}$ on crack length. In this experiment, a long Elox slot would be machined in a specimen so that the initial crack-length would be greater than tho se crack lengths for which the dependence was observed. If subsequent fracture-toughness testing revealed no dependence of $\mathbf{K}$ on $\mathbf{a}$, irrespective of how the starter crack was generated, then crack-tip damage would have to be discounted as a potential cause of the dependence. If, on the other hand, 2 dependence was observed, crack-tip damage would be indicated.

That the distribution of points in Fig. 12 may not be a true indication of scatter can be seen in Fig. 14. For any given crack longth in Fis. 14, the extreme ralues ro not diff.r by more than 2.2 MHa.m ${ }^{1}{ }^{2}$ (2 ksi. in $\left.{ }^{1} 2\right)$. Retuming to Fif. 12, in which crack length is an implicit variable, we noe that the extreme values for the same set of data differ by 4. 4 XlPa. $\mathrm{m}^{12}$ it isi. in ${ }^{1 / 2}$ ).

A limitut study was performed at room temperature io determine the difference between fracture toughness of specimens in the fatigle-precracked and in the asFloxed conditions. The results are presented in Fig. 15, which is a plot of rracture toughness is notch-root radius. It is assumed in constructing the figire that the notch-rool radius of fatigueprecracked specimens is vanishingly small on this scale, No significant influence of notch-rooi radius on $K_{\text {max }}$ can be detected with these data. Data for a particular test were ruled to be inadmissible if a crack became directionally unstable and caused arm failure. Generally, the maximum loads reached during tests in which arin failure occurred were significantly larger than those reached in tests in which the crack remained in the side groove. A rm failure occurred frequently for specimens tested in the as-Eloxed condition. Also, there was apparently a greater tendeney to arm failure at elevated temperatures than at ambient :emperatures. In about half of the tests performed at elevated temperatures, arm failure occurred on the first attempt. Cracks in these specimens occasionally did not arrest. For example, specimen GL-6 (Appendix B) was tested at $150^{\circ} \mathrm{C}$ with a $1.27 \mathrm{~mm}$ long fatigue crack. The crack stayed in the side groove, did not arrest, and 


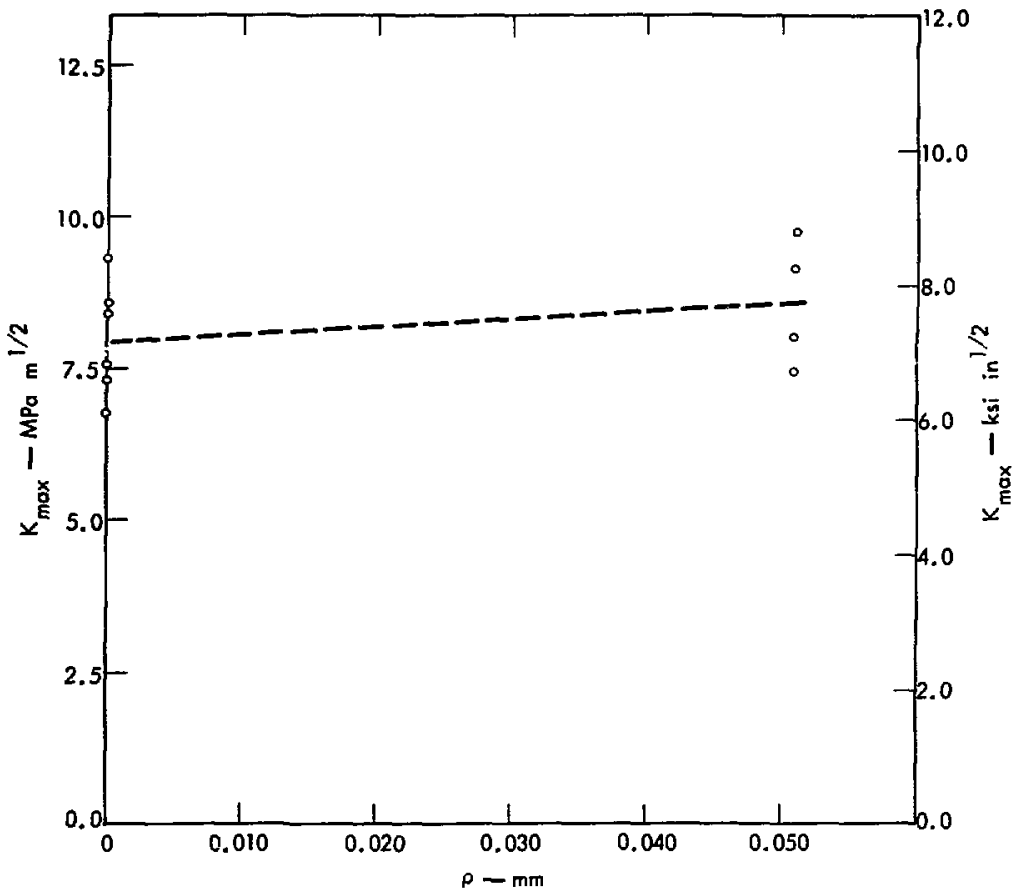

Fig. 15. Influence of notch preparation on fracture toughness ( $K_{\max }$ vs notch root
radius).

propagated through the entire length of the specimen.

\section{FRACTOGRAPHY}

An examination of fatigue- and fastfracture surfaces $w$ as made using a scanning electron microscope. In Fig. 16 (taken at 500X) a fatigue area shows isolated regions in which cleavage planes make large angles with respect to each other. The remainder of the fatigue surface appeared to be highly textured and

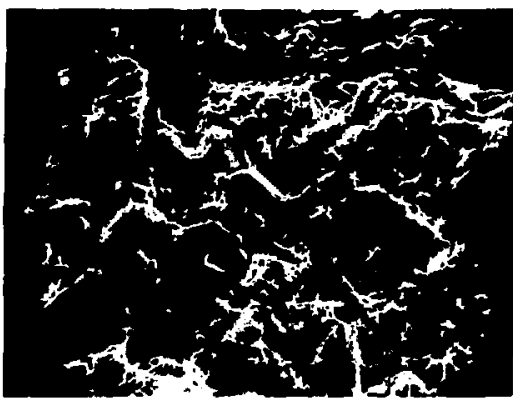

Fig. 16. Scanning electron micrograph of a fatigue region (500X). 


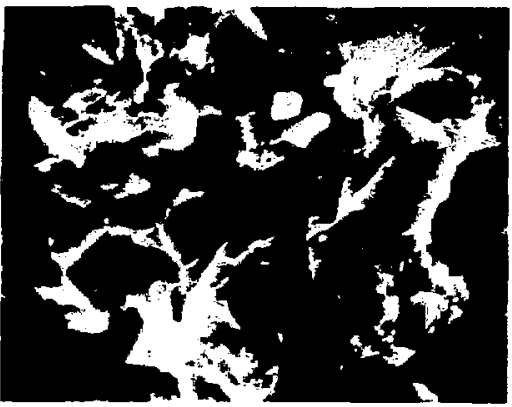

Fig. 17. Scanning electron micrograph of a fatigue region $(5000 \mathrm{x})$.

rough, as can be spen in Fig. 17 (taken at $5000 \mathrm{X}$ ). The various facets in these micrographs exhibit a wide range of sizes. There is appirently some debris on the fatigue surface. It is possivle that the peculiar appearance of these fatigue surfaces inuld, in large part, result from damage accumulated during the reversed loading procedure.

Fractouraphs of fast-fracture areas of specimens tested at room temperature and at $302 \mathrm{C}$ are shown in Fig. 18 and

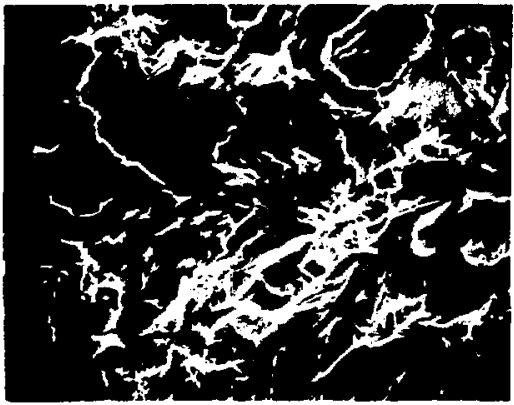

Fic. 14. Scanning electron micrograph of a tast fracture region at $23:(1000 \times)$.

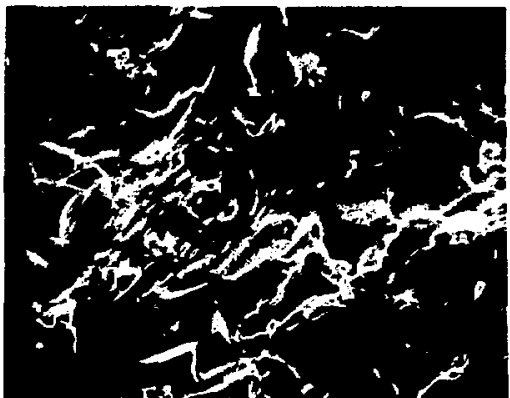

Fig. 19. Scanning electron micrograph of a fast fracture rugion at $302^{\circ} \mathrm{C}(1000 \mathrm{X})$.

Fig. 1:, respectively. Both fractographs reveai predominantly flat transgranular cleavage. There were no apparent lifferences between room-temperature and elevated-temperature fast-fracture surfaces.

The poor homogeneity of the grade of beryllium being tested is demonstrated in Fig. 20 in which can be seen evidence of foreign material which had been included in the hot pressed block. $\mathrm{X}$-radiographs taken of these specimens

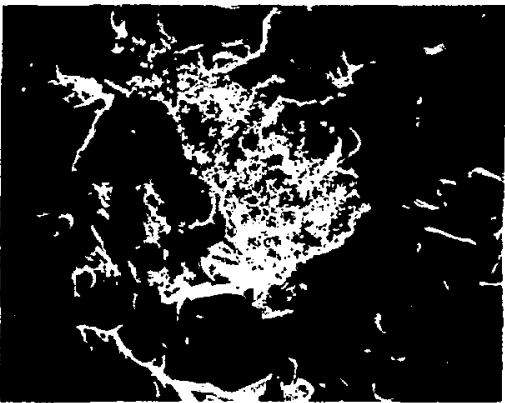

Fig. 20. Scanning electron micrograpin of an inclusion which has been intersected by a rapidly propagating crack $(1000 \mathrm{x})$. 
exhibited a substantial density of strongly absorbing particles, giving the radiographs a stippled appearance. Tht scatter in the fracture toughness data generated in this study could in large part be due to these inhomogeneities.

\section{Conclusions}

From the results of this study, the followirg conclusions can be made:

- Ising reversed-loading procedures, fatigue cracks $1.27 \mathrm{~mm}$ in length were grown (typically, in $8 \times 10^{4}$ cycles) at a fatigue stress intensity of $6.5 \mathrm{MPa} \cdot \mathrm{m}^{1 / 2}\left(5.9 \mathrm{ksi} \cdot \mathrm{in}^{1 / 2}\right)$. Cracks would not initiate or grow at lower stress intensities. Uncertainty as to the extent of plasticity and tu inning in the vicinity of the crack tip may limit the usefulness of this technique in staniard fracturetoughness testing.

- The values of $K_{\text {inax }}$ obtained from specimens with machined notches did not differ signif cantly from those obtained from fatigue-precracked specimens.

- The specimens exhibited nonlinear load-displacement records. The extent of the nonlinearity depended strongly on crack length. For short cracks, the load-displacement records satisfied ASTM requirements for linearity. Long cracks exhibited increasing compliance as applied loads increased.

- The fracture-toughness data generated indicate that for tem- peratures between $23^{\circ} \mathrm{C}$ and $30^{\circ} \mathrm{J} \mathrm{C}$ the fracture toughness of the material tested is only a weakly increasing function of temperature. At $23^{\circ} \mathrm{C}$ the mean value of toughness from 24 tests is $9.0 \mathrm{MPa} \cdot \mathrm{m}^{1 / 2}$ $\left(8,1 \mathrm{ksi} \cdot \mathrm{in}^{1 / 2}\right)$ with a lower extreme of $6.8 \mathrm{MF}: \mathrm{m}^{1 / 2}\left(6.1 \mathrm{ksi} \cdot \mathrm{in}^{1 / 2}\right)$. At $300^{\circ} \mathrm{C}$ the mean value of toughness from 7 tests is $10.8 \mathrm{MPa} \cdot \mathrm{m}^{1 / 2}$ (9.7 ksi. in ${ }^{1 / 2}$ ) with a wer extreme of $9.7 \mathrm{MPa} \cdot \mathrm{m}^{1 / 2}$ (8.5 ksi. in ${ }^{1 / 2}$ ). The room-temperature values are among the lowest ever reported for beryllium.

- Subcritical crack growth (microcracking) occurred at stress intensities as low as $60 \%$ of the critical stress intensity.

- There is no appreciable crientation effect for this material. At room temperature, the mean viniue of toughness from 18 tests of transverse specimens is $9.1 \mathrm{MPa} \cdot \mathrm{m}^{1 / 2}$ $\left(8.2 \mathrm{ksi}^{\circ}\right.$ in $^{1 / 2}$ ) whereas the mean value of toughness frcin 7 tests of longitudinal specimens is $8.6 \mathrm{MPa} \cdot \mathrm{m}^{1 / 2}\left(7.8 \mathrm{ksi} \cdot \mathrm{in}^{1 / 2}\right)$. 


\section{Acknowledgements}

The advice and guidance of tames

R. Hauber and llastiell Wejss thr nughnut the course ai this work as well as the skill[ul assistance of Hernard
A. Kuhn in testing made the project possible. Their contributions were indispensitio and are grateduly acknowledged.

\section{References}

1. D. L. Harrod, T. F. Hengstenberg, and M. I. Manjoine, 1. Mlater. \pm (3), 618 (1969).

2. W. O. Shabbits and W. A. Logston, J. Test. Eval. 1 (2), 110 (1973).

3. S. H. Gelles, Summary Report on Characteristics of Conmercial Vacuum-HotPressed Bery lium. Part II, Lawrence Livormore Labol ntory, Rept. LCRL-1358C (1972).

4. M. H. Jones, R. T. Bubsey, and W. F. Brown, Jr, J. Test, Fval. 1 (2), 100 (1973).

5. H. Conrad, J. Hurd, and D. Woodard, J. Test. Eval. 1 (2), 8:, (1973).

6. M. E. Prado, Evaluation of Fracture Toughness of Bery:lium, Lawrence Livermore Laboratory, Rept. UCID-15970, Rev. 1 (1972).

7. S. Mostovoy, P. B. Crosley, and E. J. Ripling, J. Mater. 2, 66 (1967).

8. W. Eiber, Engr. Fract. Mech. 2 (1), 37 (1970).

9. 1. Finnie and A. Saith, Int. J. Frant. ‥ 48411973$\}$.

10. S. G. Larsson and A. J. Carlsson, J. Mech. Phys. Sol. 21, 263 (1973).

11. J. Rice, J. Mech. Phys. Sol. 22, 17 (1974). 


\section{Appendix A \\ Compliance Calibration}

The following data are used in Fig. 4 to compare the experimentally observed specimen compliance and the analytically-determined compliance from Mostovoy's solution.

Table A 1. Compliance calibration data.

\begin{tabular}{lcccc}
\hline $\mathrm{a}(\mathrm{mm})$ & $\mathrm{C}_{\mathrm{o}}(\mu \mathrm{m} / \mathrm{kN})$ & $\mathrm{C}_{\mathrm{c}}(\mu \mathrm{m} / \mathrm{kN})$ & $\mathrm{C}_{\mathrm{o}}-\mathrm{C}_{\mathrm{c}}(\mu \mathrm{m} / \mathrm{kN})$ & $\mathrm{C}_{\mathrm{m}}(\mu \mathrm{m} / \mathrm{kN})$ \\
\hline 10.3 & 23.5 & 5.89 & 17.6 & 17.4 \\
11.7 & 29.7 & 6.75 & 23.0 & 22.0 \\
12.9 & 33.7 & 7.61 & 26.1 & 26.7 \\
15.5 & 46.9 & 9.61 & 37.3 & 38.3 \\
18.1 & 64.0 & 11.9 & 52.2 & 53.2 \\
20.5 & 85.8 & 14.2 & 71.5 & $\mathbf{7 0 . 4}$ \\
\hline
\end{tabular}

Compliance as observed on P-ó record:

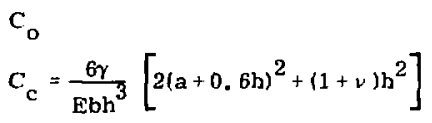

Compliance correction for location of displacement measurement:

$$
C_{c}=\frac{6 \gamma}{\mathrm{Ebh}^{3}}\left[2(\mathrm{a}+0.6 \mathrm{~h})^{2}+(1+v) \mathrm{h}^{2}\right]
$$

Mc.otovoy's expression for DCB Compliance: $C_{m}=\frac{8}{E b a^{3}}\left[(a+0.6 h)^{3}+\frac{3(1+v) a h^{2}}{4}\right]$

where
$v=0.03$
$\mathrm{h}=9.53 \mathrm{~mm}$
$\mathrm{E}=289 \mathrm{GPa}$
$\gamma=3.58 \mathrm{~mm}$
$\mathrm{b}=6.92 \mathrm{mn}$ 


\section{Appendix B}

\section{Calculation of $\mathbf{K}_{\max }$}

The following data are used to calculate $K_{\text {max }}$

Table B-1. Tabulation of experimental results.

\begin{tabular}{|c|c|c|c|c|c|c|c|}
\hline $\begin{array}{l}\text { Spec- } \\
\text { imen }\end{array}$ & $\begin{array}{c}\mathrm{T} \\
\left({ }^{\circ} \mathrm{C}\right)\end{array}$ & $\begin{array}{c}a \\
(\mathrm{~mm})\end{array}$ & $\begin{array}{c}C_{o} \\
(\mu M / k N)\end{array}$ & ${ }_{\text {max }}^{P_{\text {max }}}$ & $\frac{\mathrm{K}}{\mathrm{MPa} \cdot \mathrm{m}^{\mathrm{T}}}$ & $\frac{\mathrm{K}_{\max }}{1 / 2)\left(\mathrm{ksi} \cdot \mathrm{in}^{1 / 2}\right)}$ & Remarks \\
\hline \multirow[t]{4}{*}{ GL-1 } & 23 & 12.7 & 37 & 0.890 & 7.7 & 6.9 & \\
\hline & 23 & 16.3 & 50 & 0.917 & 9.4 & 8.5 & \\
\hline & 23 & 17.7 & 66 & 0.872 & 9.5 & B. 6 & \\
\hline & 23 & 19.4 & 69 & $0.82 B$ & 9.5 & 8.6 & Arm failure uncerțain \\
\hline GL-2 & & & & & & & $\begin{array}{l}\text { Compliance calibration } \\
\text { specimen }\end{array}$ \\
\hline$G L-3$ & 23 & 11.3 & 23 & 1.05 & 8.4 & 7. 6 & $\begin{array}{l}\text { Arm failure occurred } \\
\text { at } a=14.0, \text { making } \\
\text { subsequent tests invalid }\end{array}$ \\
\hline \multirow[t]{6}{*}{ GL-4 } & 23 & 12.7 & 23 & 0.992 & 8. 4 & 7.6 & \\
\hline & 23 & 20,3 & 69 & 0.926 & 11.0 & 9.9 & \\
\hline & 23 & 19.0 & 80 & 0.837 & 10.0 & 0.0 & \\
\hline & 23 & 22.7 & 103 & 0.837 & 11.0 & 9.9 & \\
\hline & 292 & 24.4 & 132 & 0.926 & 12.3 & 11.1 & \\
\hline & $2 B 6$ & 34.3 & 286 & 0.596 & 11.0 & 9.9 & Arm fai ure \\
\hline \multirow[t]{2}{*}{ GL-5 } & 23 & 16. 8 & $\mathbf{5 1}$ & 0.935 & 9.7 & 8.7 & \\
\hline & 23 & 17.5 & 69 & 0.939 & 10.1 & 9.1 & Arm failure uncertain \\
\hline GL- 6 & 150 & 11.8 & 26 & 1.12 & 9.3 & 8.4 & $\begin{array}{l}\text { Crack did not arrest; } \\
\text { stayed in side grooves } \\
\text { entire length of specimen }\end{array}$ \\
\hline GL-7 & & & & & & & $\begin{array}{l}\text { Specimen used in crack- } \\
\text { length-determination } \\
\text { tests (scan, } x-\text { ray and } \\
\text { dye penetrant tests) }\end{array}$ \\
\hline
\end{tabular}


Table B-1 (continued)

\begin{tabular}{ccccccc}
\hline $\begin{array}{c}\text { Spec- } \\
\text { imen }\end{array}$ & $\left(^{\circ} \mathrm{C}\right)$ & $(\mathrm{mm})$ & $\mathrm{C}_{\mathrm{o}}$ & $\mathrm{P}_{\max }$ & $\mathrm{K}_{\max }$ & \\
\end{tabular}

GL-8

Data not reliable; possible calibration error. Also, load train not aligned properly

$\begin{array}{rrrrrrr}\text { GL-9 } & 23 & 11.9 & 34 & 0.881 & 7.3 & 6.6 \\ & 23 & 15.2 & 51 & 1.05 & 10.2 & 9.2\end{array}$

Crack leaves side groove. Subsequent tests invalid

$\begin{array}{rrrrlrrr}\text { GL-10 } & 23 & 11.9 & 25 & 0.908 & 7.5 & 6.8 & \\ 301 & 13.5 & 40 & 1.19 & 10.8 & 9.7 & \\ 30 & 30.5 & 183 & 0.579 & 9.7 & 8.7 & \text { Arm faílure }\end{array}$

$\begin{array}{rrrrlrrr}\text { GL-11 } & 23 & 10.4 & 25 & 0.890 & 6.8 & 6.1 & \\ & 23 & 11.7 & 34 & 0.952 & 7.9 & 7.1 & \\ 303 & 15.0 & 34 & 0.997 & 9.4 & 8.5 & \\ 300 & 17.0 & 74 & 1.13 & 11.8 & 10.6 & \text { Arm failure }\end{array}$

GL-12

Intact, with fatigue crack. Saved for possible future testing

GL-13

Tested at $210^{\circ} \mathrm{C}$ without observing crack. Initial crack length not consistent with initial compliance. Arm failure

GL-14

21.0

86

0.828

10.1

9.1 Intact, with an arrested crack

GL-15

Intact, with fatigue crack. Saved for possible future testing

DE 1T

Arm failure occurred before an observable crack appeared in side groove 
Table B-1 (continued)

\begin{tabular}{|c|c|c|c|c|c|c|}
\hline $\begin{array}{l}\text { Spec- } \\
\text { imen }\end{array}$ & $\begin{array}{c}\cdot \mathrm{r} \\
\left({ }^{e} \mathrm{C}\right)\end{array}$ & $\begin{array}{c}\mathrm{a} \\
(\mathrm{mm})\end{array}$ & $\begin{array}{c}C_{0} \\
\left.(\mu N)^{\prime}+s N\right)\end{array}$ & $\begin{array}{l}P_{\max } \\
(\mathrm{kN})\end{array}$ & $\frac{\mathrm{K}^{\mathrm{max}}}{\left(\mathrm{MPa}+\mathrm{m}^{1 / 2}\right)\left(\mathrm{ksi} \cdot \mathrm{in} / \mathrm{T}^{2}\right)}$ & Remarks \\
\hline
\end{tabular}

IDE $2 T$

NE $3 T$

DE $4 T$

DE $5 T$

DCO $6 T$

$\begin{array}{ll}10.4 & 23 \\ 10.8 & 37 \\ 13.5 & 49\end{array}$

DCO 7T

10.4

23

1.26

1.03

1.03

1.12

8. 3

10.2

9.8

8.8

7.2

7. 5

9. 2

DCO 8T

\begin{tabular}{rrrrrrrl} 
DCO 9T 23 & 10.4 & 23 & 1.19 & 9.2 & 8.3 & \\
298 & 13.6 & 46 & 1.09 & 10.1 & 9.1 & \\
23 & 13.6 & 57 & 1.03 & 9.5 & 8.6 & Arm failure \\
& & & & & & \\
DCO 1OT 23 & 10.4 & 23 & 0.970 & 7.5 & 6.8 & \\
23 & 10.7 & 29 & & 7.9 & 7.1 & Arm failure \\
\hline
\end{tabular}

Arm failure

Sulsstantial microcracking occurred with no measu rable crack growth. Crack leares side grooves and reenters. Data not reliable.

Artn failure occurred when testing machined notch at $300^{\circ} \mathrm{C}$

Specimen destroyed by machinist

Intact. Saved for possible future testing

Saved for possible future testing

$$
K_{\max }=\left[\frac{E}{2 b_{N}\left(1-v^{2}\right)}\right]^{1 / 2}\left(\frac{d C}{d a}\right)^{1 / 2} P_{\max }
$$




where $\quad \begin{array}{rlrl}\frac{\mathrm{dC}}{\mathrm{da}} & =\frac{8}{\mathrm{Ebh}^{3}}\left[3(\mathrm{a}+0.6 \mathrm{~h})^{2}+\frac{3(1+v) \mathrm{h}^{2}}{4}\right] \\ \text { and } & \mathrm{E} & =289 \mathrm{GPa} & \mathrm{b}=8.92 \mathrm{~mm} \\ \boldsymbol{r} & =0.03 & \mathrm{~h}=9.53 \mathrm{~mm} \\ \mathrm{~b}_{\mathrm{N}} & =7.70 \mathrm{~mm} & \end{array}$

$\mathrm{IMM} / \mathrm{lt} / 1 \mathrm{mc}$ 